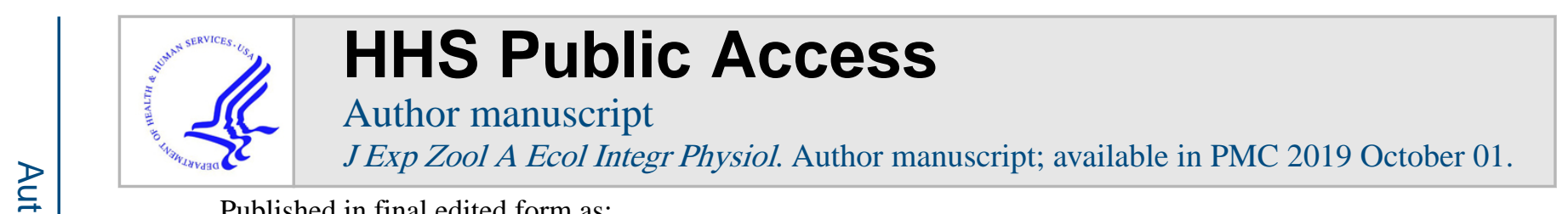

Published in final edited form as:

J Exp Zool A Ecol Integr Physiol. 2018 October ; 329(8-9): 465-472. doi:10.1002/jez.2168.

\title{
Light at night disrupts nocturnal rest and elevates glucocorticoids at cool color temperatures
}

\author{
Valentina J Alaasam ${ }^{1,{ }^{*}, \text { Richard Duncan }}{ }^{1}$, Stefania Casagrande ${ }^{2}$, Scott Davies ${ }^{3}$, Abhijaat \\ Sidher $^{1,4}$, Brett Seymoure ${ }^{5}$, Yantao Shen ${ }^{4}$, Yong Zhang ${ }^{1}$, and Jenny Q Ouyang ${ }^{1}$ \\ ${ }^{1}$ Department of Biology, University of Nevada, Reno, Reno, NV, USA \\ ${ }^{2}$ Max Planck Institute for Ornithology, Starnberg, Germany \\ ${ }^{3}$ Department of Biological Sciences, Quinnipiac University, Hamden, CT, USA \\ ${ }^{4}$ Department of Electrical and Biomedical Engineering, University of Nevada, Reno, NV, USA \\ ${ }^{5}$ Department of Biology, Colorado State University, Fort Collins, CO, USA
}

\begin{abstract}
Nighttime light pollution is quickly becoming a pervasive, global concern. Since the invention and proliferation of light-emitting diodes (LED), it has become common for consumers to select from a range of color temperatures of light with varying spectra. Yet, the biological impacts of these different spectra on organisms remain unclear. We tested if nighttime illumination of LEDs, at two commercially available color temperatures $(3000 \mathrm{~K}$ and $5000 \mathrm{~K})$ and at ecologically relevant illumination levels affected body condition, food intake, locomotor activity and glucocorticoid levels in zebra finches (Taeniopygia guttata). We found that individuals exposed to 5000K light had higher rates of nighttime activity (peaking after one week of treatment) compared to $3000 \mathrm{~K}$ light and controls (no nighttime light). Birds in the 5000K treatment group also had increased corticosterone levels from pre-treatment levels compared to $3000 \mathrm{~K}$ and control groups but no changes in body condition or food intake. Individuals that were active during the night did not consequently decrease daytime activity. This study adds to the growing evidence that the spectrum of artificial light at night is important, and we advocate the use of nighttime lighting with warmer color temperatures of $3000 \mathrm{~K}$ instead of $5000 \mathrm{~K}$ to decrease energetic costs for avian taxa.
\end{abstract}

\section{Graphical abstract}

*To whom correspondence should be addressed: Department of Biology, University of Nevada, Reno, 1664 N Virginia St., Reno, NV 89557. Telephone: 805-703-4135 valentina@ nevada.unr.edu. 


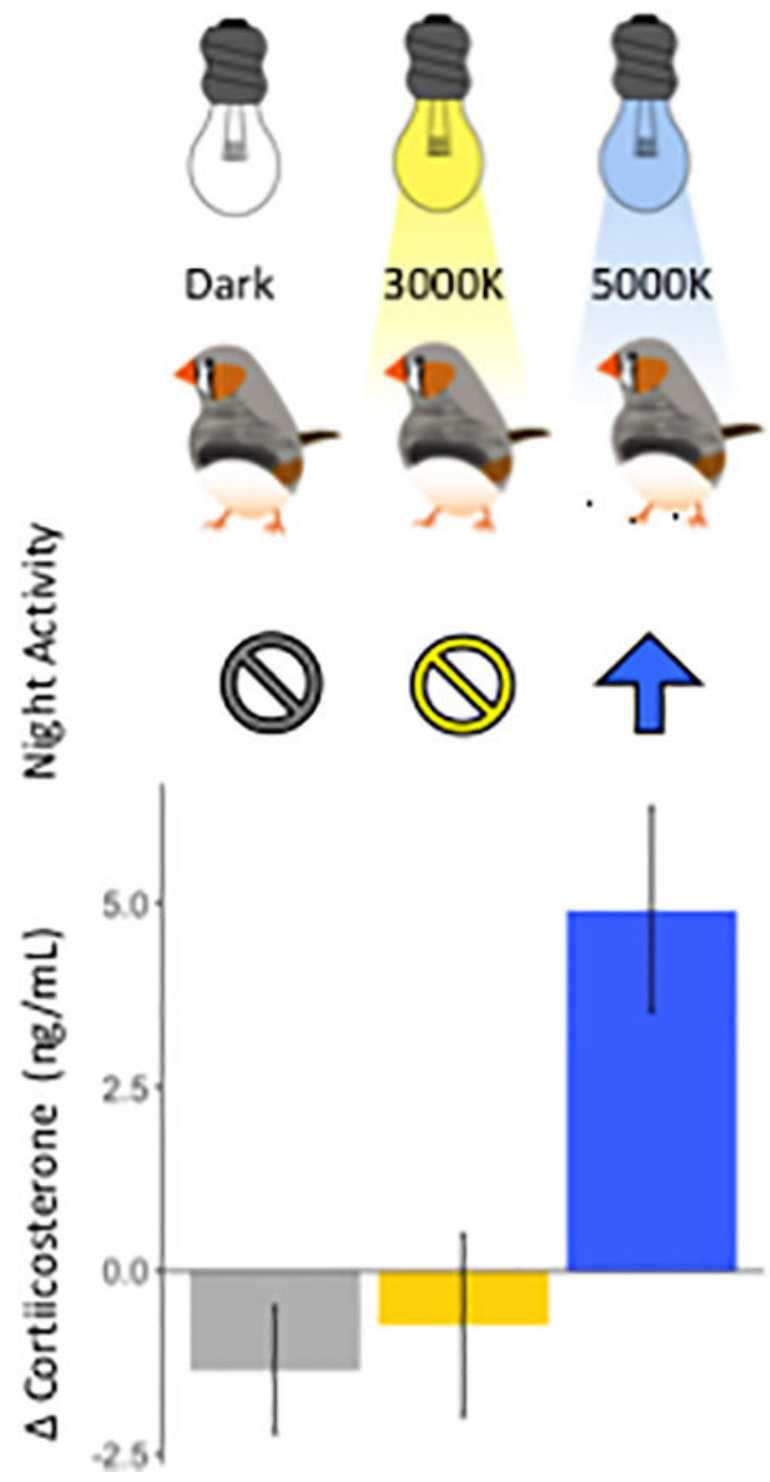

\section{Keywords}

light pollution; ALAN; hormones; metabolism; stress; glucocorticoids

\section{Introduction}

Urbanized areas worldwide are rapidly increasing, with 3.9 billion people currently living in urban areas and 6.3 billion projected to be by 2050 (United Nations World Urbanization Prospects, 2014). With this increase comes a pervasiveness of artificial light in nighttime environments (Cinzano et al., 2001). Already 83\% of the world's human population and 99\% of U.S. and European populations are living under light-polluted skies (Falchi et al., 2016). Though an indispensable tool for human safety and function, nighttime artificial illumination is disruptive for many organisms, including humans, which have evolved under natural light-dark patterns (Ouyang et al., 2018). Serious physiological effects have been 
identified across taxa, including disruption of circadian rhythm, immune function, reproductive physiology, and endocrine pathways (Bedrosian et al., 2011; de Jong et al., 2016a; Dominoni et al., 2013a; Gaston et al., 2013, 2014; Ouyang et al., 2017, Robert et al., 2015). Furthermore, there is evidence that, within species, effects of light at night differ depending on wavelength, i.e., blue light is more stimulatory for locomotor activity than red light for most taxa (Figueiro and Rea, 2010; Muheim et al., 2002; Ouyang et al., 2015).

However, studies so far have focused on isolated wavelengths (e.g. blue, green, or red) rather than comparing broad spectrum lights that are commercially available and widely used (but see Morita and Tokura, 1996 for an example of fluorescent lighting in humans).

Understanding how species perceive and are affected by different kinds of relevant artificial light is crucial for developing novel nighttime lighting strategies that will mitigate negative impacts on ecological systems (Gaston et al., 2012).

Currently, many governments, communities, and industries are switching to broad-spectrum light-emitting diode (LED) lighting due to its low cost and higher energy efficiency as compared to previous technologies. LEDs are readily available to consumers in a range of color temperatures, and we lack knowledge of this newer technology's biological implications. Color temperature, measured in Kelvin (K), refers to the hue of broadspectrum white lights and is determined by the proportion of different wavelengths emitted. For example, 5000K lighting has a higher proportion of short wavelength light, appears more blue, and is referred to as "cool" in temperature. In contrast, 3000K lighting emits more long wavelength light, appears more yellow, and is referred to as "warm" in temperature (Figure 1a). This difference in kelvin temperature may be significant, as research has shown that non-visual photoreceptors in eyes (i.e. melanopsin) and in the avian brain (i.e. melanopsin, pinopsin, and vertebrate ancient opsin) are more sensitive to short wavelengths of light (Figure 1b; Halford et al., 2009; Kuenzel et al., 2014; Wyse and Hazlerigg, 2009). These non-visual photoreceptors are the light receptors that inform cells throughout the body of changes in light levels, which can modify physiology and behavior (Davies et al., 2012a; Gaston et al., 2012; Hankins and Hughes, 2014).

Among physiological systems affected by artificial light at night (ALAN), hormonal axes may be a first line of defense (Angelier and Wingfield, 2012, Ouyang et al., 2018). One such system is the hypothalamic-pituitary-adrenal axis, which controls the release of glucocorticoids (GCs). These hormones regulate metabolism and help individuals adjust daily behaviors and physiological processes in response to unpredictable stressors, or according to predictable environmental cues, such as photoperiod (Hau and Goymann, 2015). For example, GCs typically follow a circadian rhythm and peak during more active periods within the day, as well as increase food intake and fat deposition (Hau et al., 2016; Jimeno et al., 2017). It has been shown that exposure to white broad spectrum ALAN can cause an increase in GCs in birds (Ouyang et al., 2015), as well as disrupt metabolism and lead to weight gain in humans (Figueiro and Rea, 2010; McFadden et al., 2014; Mirick et al., 2013) and rodents (Fonken et al., 2010, 2012). When chronically elevated, GCs can also influence immunity and reproductive axes; thus, they are increasingly used as a proxy for physiological health and allostatic load (Romero, 2004). Comparing physiological effects of broad-spectrum LEDs at different color temperatures that are commercially available and do not impair the quality of light for humans is of immediate importance. 
In the present study, we use LEDs of two color temperatures that the US Forest Service, among others, are considering as an alternative to previous light sources, and test their effects on activity, food intake, and glucocorticoid levels in zebra finches (Taeniopygia guttata). Birds are an ideal study system to investigate effects of ALAN given they are diurnal and rely on circadian light cycles as a cue for important biological rhythms (Gaston et al., 2014; Malik et al., 2014). For birds, proximity to light pollution can cause longer perceived day-lengths (Dominoni and Partecke, 2015), leading to earlier dawn singing (Miller, 2006; Da Silva et al., 2015), egg laying (Kempenaers et al., 2010), and onset of dawn activity (Dominoni et al., 2013b). Dominoni et al., 2013a showed that free-living birds in proximity to street lamps are exposed to an average of 0.3 lux, so we used this light level to mimic ecologically realistic exposure in a controlled experiment. We predict that exposure to 5000K LED light at night, a cooler color temperature with a higher proportion of shortwavelength light, will increase nocturnal activity, increase food intake and fat deposition, and will increase baseline GC (in birds, corticosterone), in comparison to warmer 3000K ALAN, which may mitigate such effects.

\section{Methods}

\section{Animals}

Twelve male and twelve female adult zebra finches (Taeniopygia guttata) were habituated to laboratory conditions for 38 days under 10L:14D conditions prior to the start of the experiment in Reno, $\mathrm{NV}\left(39.52^{\circ} \mathrm{N}, 119.81^{\circ} \mathrm{W}\right)$. Individuals were weighed (nearest $0.1 \mathrm{~g}$ ) and their tarsi were measured (nearest $\mathrm{mm}$ ) to calculate body condition using a scaled mass index (Peig and Green, 2009). They were housed individually in $47 \times 31 \times 36 \mathrm{~cm}$ cages with access to ad libitum food, grit, cuttlebone, and water. Food mix consisted of white proso millet, red proso millet, German millet, oat chips, canary grass seed, nylar seed, canola rape seed, flax seed, and safflower seed (Finch Mix Fancy, Volkman Seed Factory, Ceres, California, USA). Cages were fixed with two perches, one stationary and one active perch to record activity (see below). Light-occlusion shades were fitted around each cage so that birds could not see each other and so that the nighttime illumination within each cage would not affect neighboring cages. White noise was played constantly throughout habituation and the experiment to disrupt inter-individual communication and sound, thus preventing more nocturnally active birds from arousing neighbors. All procedures were approved by the University of Nevada, Reno Institutional Animal Care and Use Committee and performed in accordance with NIH guidelines.

\section{Experimental Design}

Four males and four females were randomly allocated to one of three groups: $3000 \mathrm{~K}$ nightlight, 5000K night-light, or no night-light control. Day-lights turned on at 0700h and off at $1700 \mathrm{~h}$. Night-lights turned on at $1700 \mathrm{~h}$ and off at $0700 \mathrm{~h}$ the following morning (the natural photoperiod at the time and location of the experiment).

Food was recorded once per week by weighing food before and after a 23-hour period. Each bird was provided with approximately $60 \mathrm{~g}$ of food every Monday at $1100 \mathrm{~h}$. Food remaining in the bowl or bottom of the cage was collected at $1000 \mathrm{~h}$ the following day, and the 
difference in mass was measured to the nearest $0.01 \mathrm{~g}$. Seed husks were blown off thoroughly and excrement was removed by hand before taking final food mass measurement.

Blood was collected from each bird at 0900h over a span of three days, for both pre- and post-treatment time points. Pre-treatment samples were collected six days before the beginning of the experiment. Activity began recording on day 1 of the experiment and nightlight treatment began on day 4. Post-treatment samples were collected on days $24-26$ of experiment. We were able to collect blood from 7-10 birds per day, selected randomly, and the day of collection had no effect on corticosterone levels ( $\mathrm{p}=0.97$ and 0.73 for pre- and post-treatment samples respectively). All blood samples were collected in under 3 minutes from the time we entered the room (2:18 $\pm 0: 50 \mathrm{~min})$ and this bleed time had no effect on corticosterone levels ( $p>0.6$ ). Samples were spun for $10 \mathrm{~min}$ at $16,000 \mathrm{~g}$ within 30 minutes after collection. Plasma was immediately separated and frozen at $-20^{\circ} \mathrm{C}$ until analysis. We measured weight to the nearest 0.1g with a spring scale (Pesola, Ecotone - Poland, microline 20030) and scored fat on a 0-5 scale, 0 indicating no fat stores and 5 indicating maximum fat stores.

\section{Locomotor Activity}

Active perches within each cage recorded movement on/off of the perch constantly, which is a reliable measure of circadian activity (Astheimer et al., 1992; Daan and Aschoff, 1975; Ganshirt et al., 1984). The perch activity was recorded on a Dell Precision 5810 Tower with an Intel ${ }^{\circledR}$ Xeon ${ }^{\circledR}$ Processor (E5-1620 v3) at 3.5GHz, and an AMD FirePro ${ }^{\mathrm{TM}}$ W4100 graphics card. A graphical user interface (GUI) was created in MATLAB to both record and display the activity of the birds via the active perches. The active perches were connected to an optical end-stop so that the downward force of the bird caused the wooden perch to shift down, thus blocking the signal between the emitter and the receiver on the end-stop. Upon hopping off, the active perch returns to its neutral position. Each end-stop sent a 1 or 0 to the computer depending on whether the bird was on or off the active perch, respectively. The perch activity via the end-stop was recorded through the use of four separate Arduino Mega 2560 units, each responsible for six cages. Data for all of the active perches were collected every 0.23 seconds (approximately), and totaled for every minute of activity.

\section{Lights}

Each cage was fixed with one day-light fixture and one night-light fixture mounted near the top center of the cage. Day illumination in each cage was provided by a single commercial 1.4-Watt LED aluminum fixture with a diffusing lens. The fixtures measured approximately $7 \mathrm{~cm}$ in diameter and were rated at 95 Lumens at a color temperature of 5000K. Day-light fixtures were powered by three 24-Volt non-dimmable LED drivers. Night-light fixtures were constructed using commercial LED strip lighting, cut to the desired length and mounted in an aluminum channel with a diffusing lens. The night-light fixtures measured approximately $20 \mathrm{~cm}$ long, $1.5 \mathrm{~cm}$ wide, and $0.6 \mathrm{~cm}$ deep. Each night-light fixture contained a strip of three LEDs rated at either $5000 \mathrm{~K}$ or $3000 \mathrm{~K}$ (Figure 1) and powered by commercial 12-Volt dimmable drivers, except for the control treatment fixtures, which had no LEDs inside. Light output from the night-lights was greatly attenuated by covering the back of the diffuser with black construction paper in order to reach the low level required for this 
experiment. Illuminance of all $3000 \mathrm{~K}$ and $5000 \mathrm{~K}$ night-lights was then measured in lux at perch height (15 cm from light) and at opposite corners (farthest location away from light) using an Extech Easyview Digital Light Meter (model EA13), and standardized at $0.3 \mathrm{~lx}$ \pm 0.01 . We used $0.3 \mathrm{~lx}$, as this is a realistic level of light exposure birds living in urban environments may experience, though many individuals do experience much higher exposure (Dominoni et al., 2013a). Variance in average illuminance between treatment cages was negligible (Welch Two Sample t-test, $\mathrm{t}=1.24, \mathrm{p}>0.2, \mathrm{n}=8$ ), and illumination in control (dark) cages was less than $0.01 \mathrm{~lx}$. A programmable commercial timer switched AC power on and off to all LED drivers (day- and night-lights).

\section{Corticosterone Assay}

We measured plasma corticosterone (cort) using enzyme-linked immunosorbent assays (Enzo Life Sciences, lot\# 12021512D; Farmingdale, NY, USA) following manufacturer instructions. We first validated this assay for zebra finches by using serial dilutions of plasma (1:10, 1:20, and 1:40), with two concentrations of steroid displacement reagent (SDR; $0.5 \%$ and $1 \%$ of plasma volume) and a standard curve. We determined that for our subsequent assays, plasma would be diluted 1:20 at SDR 1\%. We randomized samples across plates, but always made sure to include before and after treatment samples of the same bird next to each other, and included three pooled zebra finch plasma samples in the beginning, middle, and end of the plate. Intra- and inter- plate $\mathrm{CV}$ calculated from pooled plasma run in triplicates was $1.7 \%$ and $2.5 \%$, respectively.

\section{Statistical Analyses}

We conducted statistical analyses using R (v. 3.1.2). All final models met assumptions, and $a=0.05$. We used a generalized linear mixed model (Poisson distribution and log link function) to test if nighttime activity was affected by an interaction of treatment $\times$ day while controlling for sex and individual as a random effect, in a repeated measures design. We used general linear models to determine whether changes in cort, body condition, fat score, and food consumption varied between treatments while controlling for sex and the pretreatment condition. All changes in physiological variables were measured as the difference between post-treatment and pre-treatment levels. For example, changes in body condition were measured as body condition after treatment-body condition pre-treatment with sex and pre-treatment body condition as covariates. For changes in cort levels, we controlled for initial body condition because body condition is known to be correlated with cort. We used Tukey posthoc tests to determine if the interaction of treatment and day differed in pairwise comparisons. Lastly, we tested whether nighttime and total (day and night combined) activity levels were related to changes in cort levels while controlling for sex and body condition, and with individual as a random effect to control for repeated measures.

\section{Results}

Prior to the start of the experiment, there were no differences in cort levels, food consumption, body weight, fat, or body condition between treatment groups (all p-values $>0.1$ ). There were also no pre-treatment differences in nighttime activity ( $p=0.44)$ or total 
activity ( $p=0.89$ ) between treatments. We did not find any effect of treatment on change in weight, fat deposition, or food consumption throughout the experiment (all p-values $>0.07$ ).

Treatment had a significant effect on nighttime activity (Table 1; Figures 2,3). Post-hoc Tukey tests show a significant difference in nighttime activity between $5000 \mathrm{~K}$ treatment and control groups (estimate $=6.13 ; \mathrm{CI}=10.23,1.99 ; p<0.002$ ). Nighttime activity was not different between control and $3000 \mathrm{~K}$ treatment groups $(\mathrm{p}=0.1)$ or between $3000 \mathrm{~K}$ and $5000 \mathrm{~K}$ treatment groups $(p=0.3)$. There was no effect of treatment on daytime activity ( $\mathrm{F}=$ $0.86, p=0.42)$.

There was also a significant effect of treatment on individual changes in corticosterone levels (Table 2; Figure 4). Post-hoc Tukey tests revealed significant differences between $5000 \mathrm{~K}$ and $3000 \mathrm{~K}$ treatments (estimate $=5.64 ; \mathrm{CI}=1.44,9.84 ; p=0.008$ ), and between $5000 \mathrm{~K}$ and control (estimate $=6.25,10.45 ; p=0.003$ ), but no difference between control and $3000 \mathrm{~K}$ treatment $(p=0.92)$. On average, cort levels increased $4.97 \mathrm{ng} / \mathrm{mL}$ in the $5000 \mathrm{~K}$ treatment group $(\mathrm{CI}=0.74,9.20 ; p=0.01)$, but did not change significantly in control and $3000 \mathrm{~K}$ treatment groups $(p>0.9)$. Sex, pre-treatment cort level, and pre-treatment body condition had no effect on change in cort levels (Table 2). There was no effect of individual change in cort on nighttime activity or total activity ( $>0.1)$.

\section{Discussion}

We used zebra finches in a controlled repeated measures experiment to determine the impacts of exposure to ecologically relevant nighttime light levels. We found that the responses of nighttime activity and cort levels were dependent on the color temperature of the LED, whereby exposure to 5000K LED night-lights, but not $3000 \mathrm{~K}$ or control treatments, increased nighttime activity and cort levels over a three week experimental period. Additionally, we used a low level of illuminance $(0.3 \mathrm{~lx})$ not much brighter than what animals may experience under a full moon (Rich and Longcore, 2006), as compared to previous studies (Bedrosian et al., 2013; Burger, 1949; Raap et al., 2016a, b; Titulaer et al., 2012; Yorzinski et al., 2015).

For birds in the $5000 \mathrm{~K}$ night-light treatment, nighttime activity patterns significantly differed from the $3000 \mathrm{~K}$ and control groups in both slope and intercept without changes in total locomotor activity. This pattern of activity difference is consistent with that of an experiment on dose-dependent light intensity levels on nighttime activity in free-living great tits (Parus major, de Jong et al., 2016a). However, if we compare our activity results with the actograms presented by de Jong et al., who used 0.1 and $0.5 \mathrm{~lx}$, their actograms suggest there was a shift in circadian rhythms, i.e. an earlier onset of dawn activity. In contrast, our experiment (using $0.3 \mathrm{~lx}$ ) shows that $5000 \mathrm{~K}$ treatment individuals were highly active throughout the night (Figure 2). Moreover, nighttime activity for the $5000 \mathrm{~K}$ treatment peaked after 7 days of treatment and individuals lowered their nighttime activity levels toward the end of the experiment (Figure 3). These differences can potentially be attributed to differences in species, experimental period, or type of LED used. One commonality between these two studies is that short wavelength light affects nighttime activity levels, but how the pattern manifests differs by experiment. Importantly, nighttime activity did not 
differ significantly between the $3000 \mathrm{~K}$ and control treatments, suggesting that $3000 \mathrm{~K}$ ALAN did not disrupt nocturnal rest.

The increase in nocturnal activity in $5000 \mathrm{~K}$ treatment birds was paralleled by a withinindividual increase in cort levels. If we approximate the $5000 \mathrm{~K}$ treatment to white nightlight treatments (see spectral compositions in Figure 1 and Figure S1 in Ouyang et al., 2015), the magnitude of increase in cort we document here is similar to a study on freeliving great tits (Ouyang et al., 2015). Most studies on free-living animals report high variation in individual physiological responses to ALAN and whether this variation represents differential quality, phenotypic plasticity or avoidance of ALAN remains unclear (de Jong et al., 2016b). Here, we have reduced these sources of variation. However, it is important to note that the zebra finches were born in captivity and presumably have not been exposed to any light at night (natural or artificial) in their lifetime, in contrast to studies on wild birds.

We found $5000 \mathrm{~K}$ treatment birds maintained higher levels of nocturnal activity and withinindividual increases in cort levels without increasing food consumption and without losing body mass. Even when nocturnal activity for $5000 \mathrm{~K}$ individuals was highest (days 9-13, Figure 3), food intake (measured on day 12) did not differ from controls. Additionally, individuals in $5000 \mathrm{~K}$ treatment did not change their daytime locomotor activity despite increasing nighttime activity. However, if we continued the treatment for more time, it is possible that pathology and damage can occur (Bedrosian et al., 2011; Raap et 1., 2016b). Alternatively, if nighttime activity of the $5000 \mathrm{~K}$ treatment birds continued to return to normal levels, as the pattern suggests, perhaps individuals can acclimate to nighttime light levels of 5000K lights under 0.31x. Again, there was no difference measured between 3000K and control treatments, suggesting that zebra finches respond to the cool color temperature lights (emitting a higher proportion of short-wavelength light), similar to studies on two different vertebrate taxa (Bedrosian et al., 2011, 2013; Migaud et al., 2007).

The underlying mechanism explaining differential responses to $5000 \mathrm{~K}$ and $3000 \mathrm{~K}$ light are potentially related to the spectral sensitivities of the non-visual photoreceptors (Ruby et al., 2002). We did not measure direct effects on the non-visual photoreceptors; thus, we cannot state specifically which non-visual photoreceptors and respective hormones are responsible for the differences in activity between the two light treatments. Nevertheless, non-visual photoreceptors are more sensitive to short wavelengths of light (Davies et al., 2012b; Kuenzel et al., 2014), and one potential explanation for our results is that the non-visuals photoreceptors were stimulated more by the 5000K LED than the 3000K LED. Our hypothesis is consistent with previous research, which has shown that short-wavelength light at night can suppress melatonin and alter daily activity patterns (Dominoni, 2015; Haim and Zubidat, 2015; Navara and Nelson, 2007). Lastly, the increased activity under light conditions that better match spectrally to natural sunlight is expected, as the birds' nonvisual photoreceptors are still being activated as though it is daytime.

Following this experiment and with the support of other studies on both laboratory and experimental vertebrate animals (Bedrosian et al., 2013; Migaud et al., 2007; Ouyang et al., 2015), we advocate warm color temperature white light as nighttime illumination. However, 
it is important to note that we used a low level of illuminance based on what free-living birds may experience, and that light at $3000 \mathrm{~K}$ may still attract insects and other phototaxic species (Knop et al. 2017). Long wavelength light at higher intensities may also have other implications, such as increased fertility (Li et al., 2014). Still, using broad spectrum LED lighting does not disrupt human visibility, and is commercially-available in a wide range of color temperatures. Warmer, $3000 \mathrm{~K}$ lights represent a viable alternative to shorter wavelength lights in terms of activity and cort levels, at least for some diurnal vertebrate species. We urge follow up of light spectra studies in field settings in addition to studies in non-model organisms to form a holistic management plan for urban and rural nighttime lighting conditions to reduce the impacts of light pollution.

\section{Acknowledgments}

We thank C Branch, T Fruth, R Fung, A Grant, P Grossman, D Kozlovsky, J Liou, K Moore, D Marquez, C Munguia, A Pitera, and D Vijay for assistance. JQO is supported by National Institute of General Medical Sciences of the National Institutes of Health under grant number P20 GM103650. VJA is support by a University of Nevada Graduate Dean Fellowship. BMS is funded through a National Park Service Natural Sounds and Night Skies Division Postdoctoral Fellowship.

\section{References}

Angelier F, Wingfield JC. Importance of the glucocorticoid stress response in a changing world: Theory, hypotheses and perspectives. General and Comparative Endocrinology. 2012; 190:118-128.

Da Silva A, Valcu M, Kempenaers B. Light pollution alters the phenology of dawn and dusk singing in common European songbirds. Phil. Trans. R. Soc. B. 2015; 370(1667):20140126. Published 16 March 2015. doi: 10.1098/rstb.2014.0126 [PubMed: 25780238]

Astheimer LB, Buttemer WA, Wingfield JC, et al. Interactions of Corticosterone with Feeding, Activity and Metabolism in Passerine Birds. Scandinavian Journal of Ornithology. 1992; 23(3):355365.

Bedrosian TA, Aubrecht TG, Kaugars KE. , et al. Brain, Behavior, and Immunity. Vol. 34. Elsevier Inc; 2013. Artificial light at night alters delayed-type hypersensitivity reaction in response to acute stress in Siberian hamsters; 39-42. Available from:

Bedrosian TA, Fonken LK, Walton JC, et al. Chronic exposure to dim light at night suppresses immune responses in Siberian hamsters. Biology letters. 2011; 7(3):468-71. Available from: http:// www.pubmedcentral.nih.gov/articlerender.fcgi? artid=3097873\&tool=pmcentrez\&rendertype=abstract. [PubMed: 21270021$]$

Burger JW. A review of experimental investigations on seasonal reproduction in birds. Wilson Bull. 1949; 61(4):211-230.

Cinzano P, Falchi F, Elvidge CD. The first World Atlas of the artificial night sky brightness. Monthly Notices of the Royal Astronomical Society. 2001; 328(3):689-707.

Daan S, Aschoff J. Circadian rhythms of locomotor activity in captive birds and mammals: Their variations with season and latitude. Oecologia. 1975; 18(4):269-316. [PubMed: 28308918]

Davies WIL, Turton M, Peirson SN, et al. Vertebrate ancient opsin photopigment spectra and the avian photoperiodic response. Biology Letters. 2012a; 8(2):291-294. Available from: http:// rsbl.royalsocietypublishing.org/cgi/doi/10.1098/rsbl.2011.0864. [PubMed: 22031722]

Davies WIL, Turton M, Peirson SN, et al. Vertebrate ancient opsin photopigment spectra and the avian photoperiodic response. Biology Letters. 2012b; 8(2):291-294. [PubMed: 22031722]

de Jong M, Jeninga L, Ouyang JQ. , et al. Physiology and Behavior. Vol. 155. Elsevier Inc; 2016 a. Dose-dependent responses of avian daily rhythms to artificial light at night; 172-179. Available from:

de Jong M, Ouyang JQ, Van Grunsven RH a, et al. Do wild great tits avoid exposure to light at night? PLoS ONE. 2016b; 11(6):1-8. 
Dominoni D, Quetting M, Partecke J. Artificial light at night advances avian reproductive physiology. Proceedings of the Royal Society B: Biological Sciences. 2013a; 280(1756):20123017-20123017. Available from: http://rspb.royalsocietypublishing.org/cgi/doi/10.1098/rspb.2012.3017. [PubMed: 23407836]

Dominoni DM, Helm B, Lehmann M, et al. Clocks for the city: circadian differences between forest and city songbirds. Proceedings of the Royal Society B: Biological Sciences. 2013b; 280(1763): 20130593-20130593. Available from: http://rspb.royalsocietypublishing.org/cgi/doi/10.1098/rspb. 2013.0593. [PubMed: 23740778]

Dominoni Davide M, Goymann W, Helm B, et al. Urban-like night illumination reduces melatonin release in European blackbirds (Turdus merula): implications of city life for biological timekeeping of songbirds. Frontiers in Zoology. 2013c; 10(1):60. Available from: http:// frontiersinzoology.biomedcentral.com/articles/10.1186/1742-9994-10-60. [PubMed: 24090446]

Dominoni D. Journal of Ornithology. Vol. 156. Springer Berlin Heidelberg; 2015. The effects of light pollution on biological rhythms of birds: an integrated, mechanistic perspective; 409-418.

Dominoni DM, Partecke J. Does light pollution alter daylength ? A test using light loggers on freeranging European blackbirds (Turdus merula) Does light pollution alter daylength ? A test using light loggers on free-ranging European blackbirds (Turdus merula). 2015 May.

Falchi F, Cinzano P, Duriscoe D, et al. The new world atlas of artificial night sky brightness. Science Advances. 2016; 2(6):e1600377-e1600377. Available from: http:// advances.sciencemag.org/cgi/doi/10.1126/sciadv.1600377. [PubMed: 27386582]

Figueiro MG, Rea MS. The effects of red and blue lights on circadian variations in cortisol, alpha amylase, and melatonin. International Journal of Endocrinology. 2010; 2010

Fonken LK, Workman JL, Walton JC, et al. Light at night increases body mass by shifting the time of food intake. Proceedings of the National Academy of Sciences. 2010; 107(43):18664-18669. Available from: http://www.pnas.org/cgi/doi/10.1073/pnas.1008734107.

Fonken LK, Haim A, Nelson RJ. Dim Light at Night Increases Immune Function in Nile Grass Rats, a Diurnal Rodent. CHRONOBIOLOGY INTERNATIONAL. 2012; 29(1):26-34. [PubMed: 22217098]

Ganshirt G, Daan S, Gerkema MP. Arrhythmic perch hopping and rhythmic feeding of starlings in constant light: Separate circadian oscillators? Journal of Comparative Physiology A. 1984; 154(5): 669-674.

Gaston KJ, Davies TW, Bennie J, et al. Reducing the ecological consequences of night-time light pollution: Options and developments. Journal of Applied Ecology. 2012; 49(6):1256-1266. [PubMed: 23335816]

Gaston KJ, Bennie J, Davies TW, et al. The ecological impacts of nighttime light pollution : a mechanistic appraisal. 2013; 88:912-927.

Gaston KJ, Duffy JP, Gaston S, et al. Human alteration of natural light cycles: causes and ecological consequences. Oecologia. 2014; 176(4):917-931. [PubMed: 25239105]

Haim A, Zubidat AE. Artificial light at night : melatonin as a mediator between the environment and epigenome. Philosophical transactions of the Royal Society of London. Series B, Biological sciences. 2015; 370:20140121. [PubMed: 25780234]

Halford S, Pires SS, Turton M, et al. VA Opsin-Based Photoreceptors in the Hypothalamus of Birds. Current Biology. 2009; 19(16):1396-1402. [PubMed: 19664923]

Hankins MW, Hughes S. Current Biology. Vol. 24. Elsevier Ltd; 2014. Vision: Melanopsin as a novel irradiance detector at the heart of vision; R1055-R1057. Available from:

Hau M, Goymann W. Endocrine mechanisms, behavioral phenotypes and plasticity: Known relationships and open questions. Frontiers in Zoology. 2015; 12(1):1-15. [PubMed: 25628752]

Hau M, Casagrande S, Ouyang JQ. , et al. Advances in the Study of Behavior. Elsevier Ltd; 2016. Glucocorticoid-Mediated Phenotypes in Vertebrates: Multilevel Variation and Evolution. Available from:

Jimeno B, Briga M, Verhulst S., et al. Hormones and Behavior. Vol. 93. Elsevier Inc; 2017. Effects of developmental conditions on glucocorticoid concentrations in adulthood depend on sex and foraging conditions; $175-183$. Available from: 
Kempenaers B, Borgström P, Loës P, et al. Artificial night lighting affects dawn song, extra-pair siring success, and lay date in songbirds. Current Biology. 2010; 20(19):1735-1739. [PubMed: 20850324]

Knop E, Zoller L, Ryser R, et al. Artificial Light at Night as a New Threat to Pollination. Nature. 2017; 548:206. [PubMed: 28783730]

Kuenzel WJ, Kang SW, Zhou ZJ. Exploring avian deep-brain photoreceptors and their role in activating the neuroendocrine regulation of gonadal development. Poultry science. 2014; 94(4): 786-798.

Li D, Zhang L, Yang M, et al. The effect of monochromatic light-emitting diode light on reproductive traits of laying hens. Journal of Applied Poultry Research. 2014; 23(3):367-375.

Malik S, Yadav G, Rani S, et al. Light wavelength dependent circadian and seasonal responses in blackheaded bunting. Indian Journal of Experimental Biology. 2014; 52(5):448-459. [PubMed: 24851407]

McFadden E, Jones ME, Schoemaker MJ, et al. The relationship between obesity and exposure to light at night: Cross-sectional analyses of over 100,000 women in the breakthrough generations study. American Journal of Epidemiology. 2014; 180(3):245-250. [PubMed: 24875371]

Migaud H, Cowan M, Taylor J, et al. The effect of spectral composition and light intensity on melatonin, stress and retinal damage in post-smolt Atlantic salmon, Salmo salar. Aquaculture. 2007; 270(1-4):390-404.

Miller MW. Apparent Effects of Light Pollution on Singing Behavior of American Robins. The Condor. 2006; 108(1):130-139. Available from: http://www.jstor.org/stable/4123202\%5Cnhttp:// www.jstor.org/stable/pdfplus/4123202.pdf?acceptTC=true.

Mirick DK, Bhatti P, Chen C, et al. Night shift work and levels of 6-sulfatoxymelatonin and cortisol in men. Cancer Epidemiology Biomarkers and Prevention. 2013; 22(6):1079-1087.

Morita T, Tokura H. Effects of Lights of Different Color Temperature on the Nocturnal Changes in Core Temperature and Melatonin in Humans. Journal of Physiological Anthropology. 1996; 15(5): 243-246. [PubMed: 8979406]

Muheim R, Bäckman J, Åkesson S. Magnetic compass orientation in European robins is dependent on both wavelength and intensity of light. The Journal of Experimental Biology. 2002; 205:38453856. [PubMed: 12432008]

Navara KJ, Nelson RJ. The dark side of light at night: Physiological, epidemiological, and ecological consequences. Journal of Pineal Research. 2007; 43(3):215-224. [PubMed: 17803517]

Ouyang JQ, de Jong M, Hau M, et al. Stressful colours: corticosterone concentrations in a free-living songbird vary with the spectral composition of experimental illumination. Biology Letters. 2015; 11(8):20150517. Available from: http://rsbl.royalsocietypublishing.org/lookup/doi/10.1098/rsbl. 2015.0517. [PubMed: 26311159]

Ouyang JQ, de Jong M, van Grunsven RH a. Restless roosts: Light pollution affects behavior, sleep, and physiology in a free-living songbird. Global Change Biology. 2017 Apr.:1-8.

Ouyang JQ, Davies S, Dominoni D. Hormonally mediated effects of artificial light at night on behavior and fitness: linking endocrine mechanisms with function. The Journal of Experimental Biology. 2018; 221(6)

Peig J, Green AJ. New perspectives for estimating body condition from mass/length data: The scaled mass index as an alternative method. Oikos. 2009; 118(12):1883-1891.

Raap T, Casasole G, Costantini D, et al. 2016a. Artificial light at night affects body mass but not oxidative status in free-living nestling songbirds: an experimental study. SCIENTIFIC REPORTS. 6

Raap T, Casasole G, Pinxten R. , et al. Environmental Pollution. Vol. 218. Elsevier Ltd; 2016b. Early life exposure to artificial light at night affects the physiological condition: An experimental study on the ecophysiology of free-living nestling songbirds; 909-914. Available from:

Rich C, Longcore T. Ecological consequences of artificial night lighting. Washington, DC: Island Press; 2006.

Robert KA, Lesku JA, Partecke J, et al. Artificial light at night desynchronizes strictly seasonal reproduction in a wild mammal. Proceedings. Biological sciences / The Royal Society. 2015; 282(1816):20151745-.doi: 10.1098/rspb.2015.1745 
Romero LM. Physiological stress in ecology: Lessons from biomedical research. Trends in Ecology and Evolution. 2004; 19(5):249-255. [PubMed: 16701264]

Ruby NF, Brennan TJ, Xie X, et al. Role of Melanopsin in Circadian Responses to Light. Science. 2002; 298(5601):2211-2213. [PubMed: 12481140]

Titulaer M, Spoelstra K, Lange CYMJG, et al. Activity patterns during food provisioning are affected by artificial light in free living great tits (parus major). PLoS ONE. 2012; 7(5):5-8.

United Nations, Department of Economic and Social Affairs, Population Division. World Urbanization Prospects: The 2014 Revision, Highlights (ST/ESA/SER.A/352). 2014

Wyse C, Hazlerigg D. Seasonal Biology: Avian Photoreception Goes Deep. Current Biology. 2009; 19(1978):687-689.

Yorzinski JL, Chisholm S, Byerley SD, et al. Artificial light pollution increases nocturnal vigilance in peahens. PeerJ. 2015; 3:e1174. Available from: https://peerj.com/articles/1174. [PubMed: 26339552] 


\section{Research highlights}

Exposure to dim ( 0.3 lux) 5000K LED light at night caused an increase in nocturnal activity (peaking after 7 days) and baseline corticosterone (measured after 3 weeks) in captive zebra finches, relative to $3000 \mathrm{~K}$ light which had no effect. 

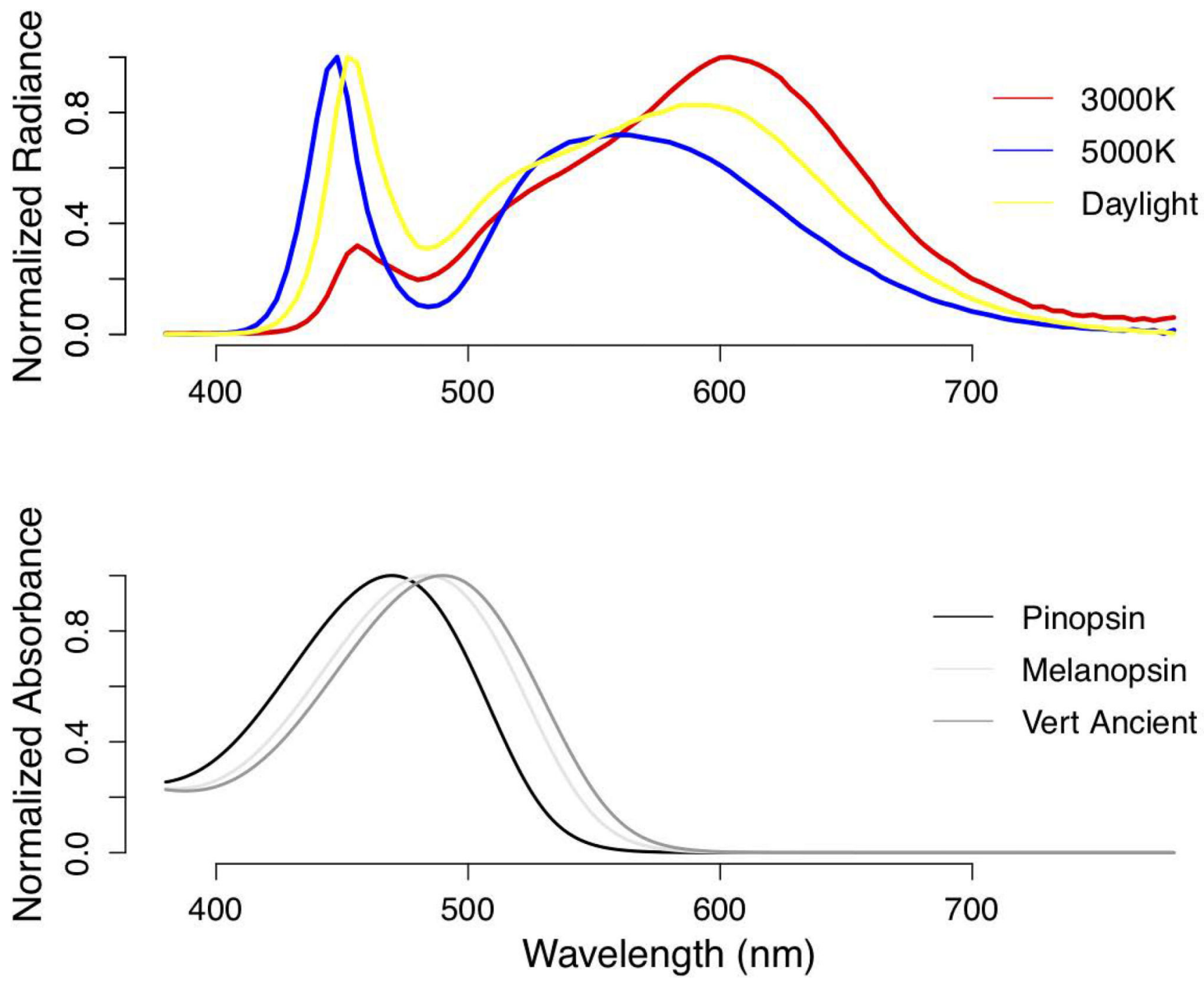

Figure 1. 

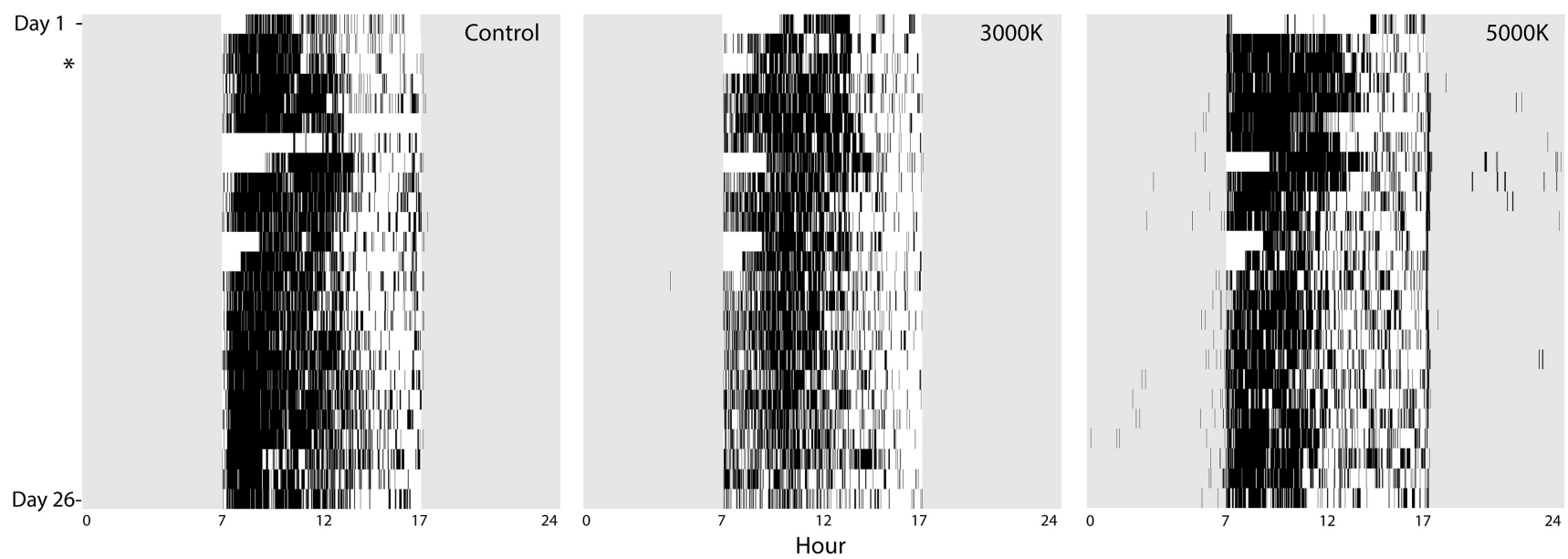

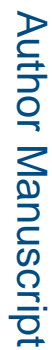

Figure 2.

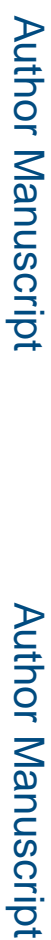

J Exp Zool A Ecol Integr Physiol. Author manuscript; available in PMC 2019 October 01. 


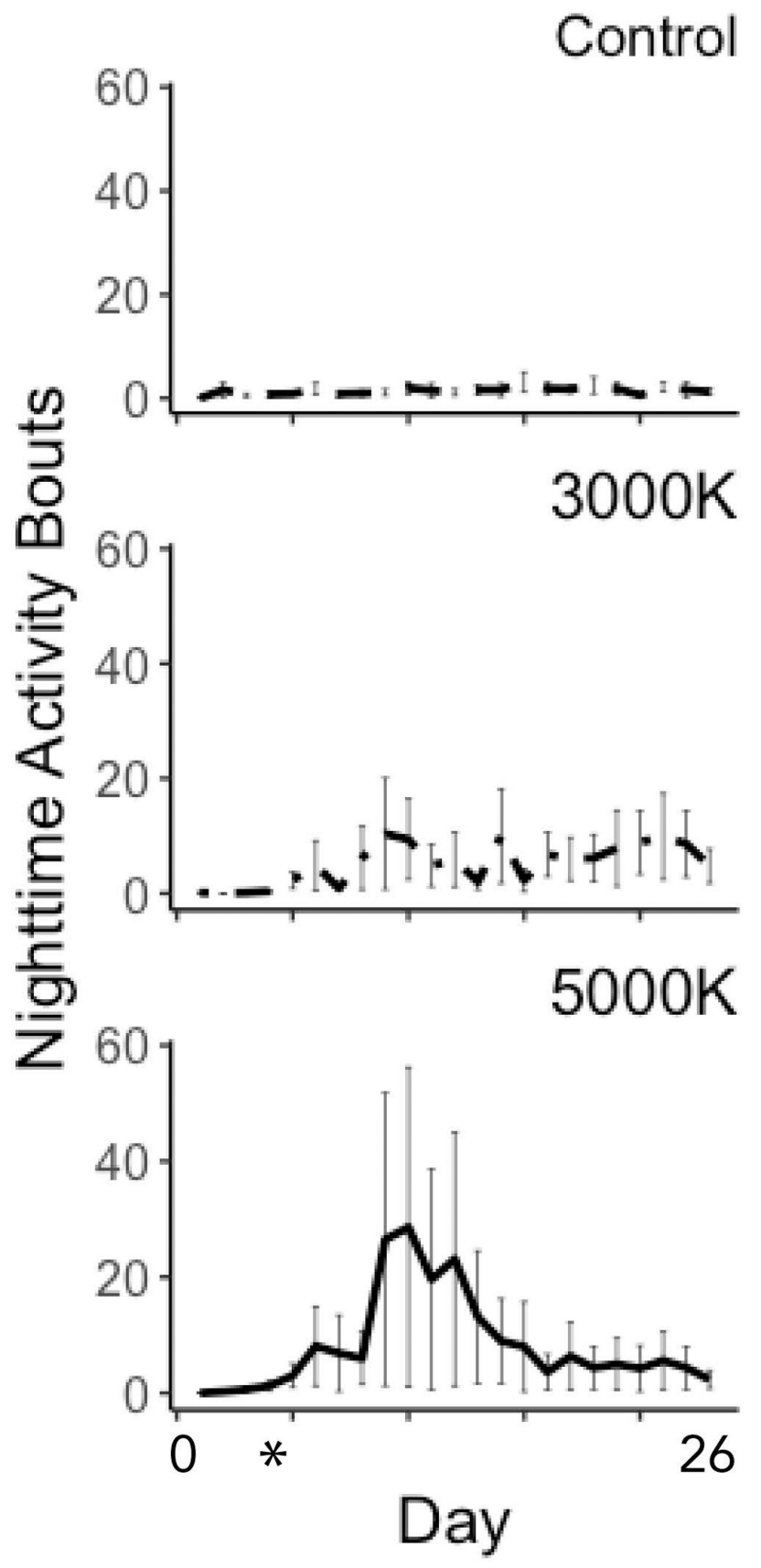

Figure 3 . 


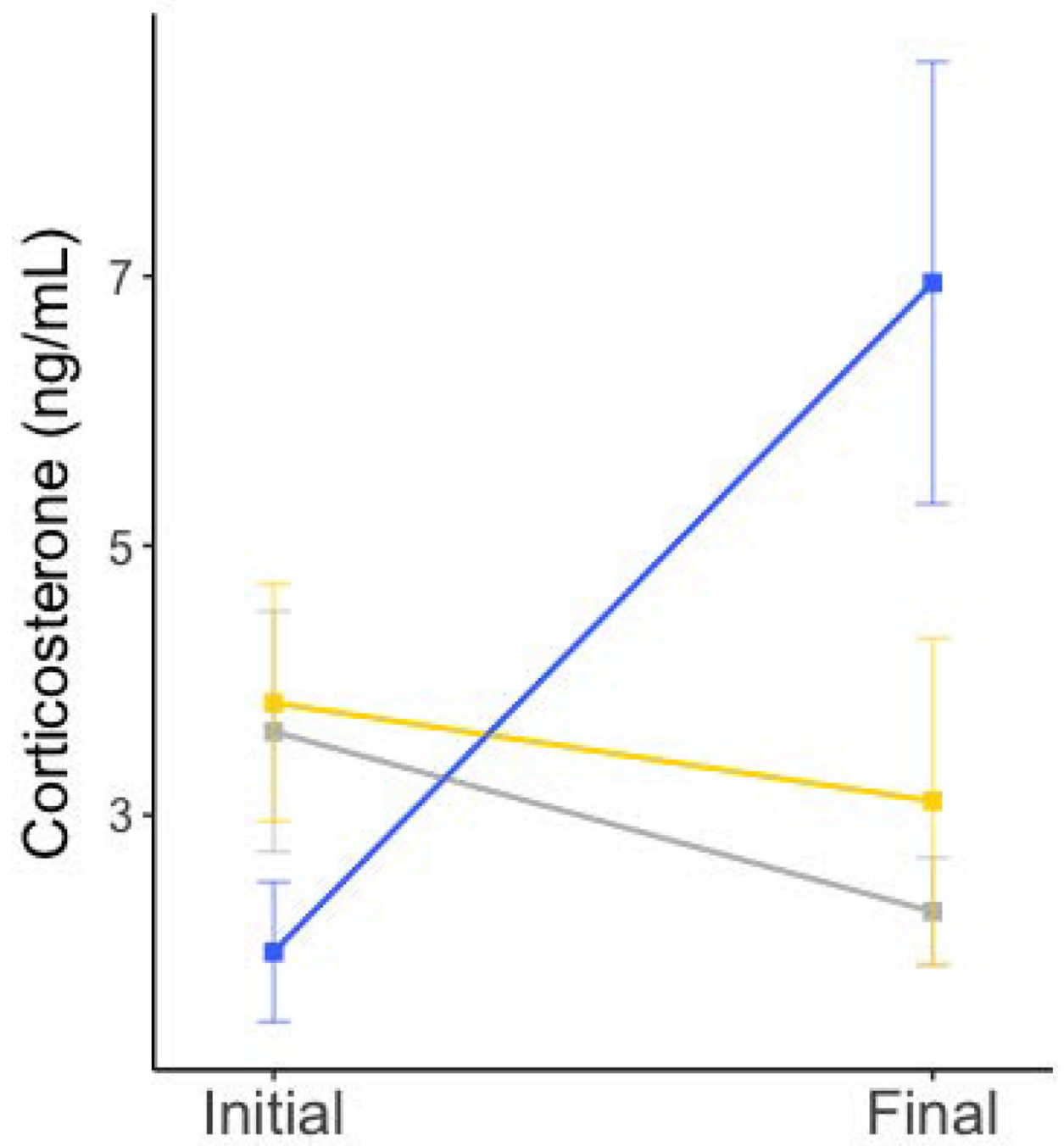

- Control

Figure 4. 


\section{Table 1}

Generalized linear mixed model using Poisson distribution of nighttime activity, including day and treatment interaction, with individual as a random effect.

\begin{tabular}{lccrc}
\hline Variable & Estimate & se & $z$ & $p$ \\
\hline Treatment $\times$ Day & 0.01 & 0.00 & -8.05 & $<0.0001^{*}$ \\
Treatment & 0.19 & 0.17 & 1.10 & 1.27 \\
Day & 0.06 & 0.01 & 8.66 & $<0.0001^{*}$ \\
Sex & 0.16 & 0.69 & 0.23 & 0.82 \\
\hline
\end{tabular}

Asterisks identify significant relationships. 


\section{Table 2}

Linear model of change in baseline corticosterone (final - initial levels) by treatment, including fixed effects of sex, pre-treatment cort, and pre-treatment body condition.

\begin{tabular}{lrrrc}
\hline Variable & Estimate & se & $\boldsymbol{t}$ & $\boldsymbol{p}$ \\
\hline Treatment & 0.89 & 0.39 & 2.30 & $0.03^{*}$ \\
Pre-treatment cort & -0.79 & 0.45 & -1.74 & 0.10 \\
Pre-treatment body condition & 0.39 & 0.52 & 0.75 & 0.46 \\
Sex & -0.43 & 1.76 & -0.25 & 0.81 \\
\hline
\end{tabular}

Asterisks identify significant relationships. 